Responsible Editor: Maria Dolores Sánchez-Fernández, Ph.D. Associate Editor: Manuel Portugal Ferreira, Ph.D. Evaluation Process: Double Blind Review pelo SEER/OJS

\title{
MAYRIT ON: UN NUEVO TURISMO CULTURAL-RELIGIOSO
}

\section{MAYRIT ON: A NEW CULTURAL-RELIGIOUS TOURISM}

\author{
Pilar Sanchez ${ }^{1}$ \\ Ruth Fernandez-Hernandez 2 \\ ${ }^{1}$ ESIC Business \& Marketing School - Spain \\ E-mail: pilar.sanchez@esic.edu \\ ${ }^{2}$ ESIC Business \& Marketing School - Spain \\ E-mail: ruth.fernandez@esic.edu
}

Received on August 14, 2018

Approved on December 21, 2018

(c) (1) (8)

(3) $f$ in $\square$

\begin{abstract}
RESUMÉN
Las nuevas tecnologías han supuesto un cambio en los consumidores respecto a la forma de vivir, pensar, viajar, decidir y comprar. Estamos en la sociedad de la ubicuidad y la conectividad. El consumidor se ha adaptado a la nueva realidad y, por ende, a la nueva comunicación. Exige a las empresas e instituciones mayor participación y capacidad de decisión. Los expertos en Marketing y Comunicación trabajamos con esa premisa de adaptación, el one to one es parte de nuestra planificación estratégica. En el entorno Internet se están consolidando las Nuevas Tecnologías. El consumidor interactúa con la empresa, ya no es un mero receptor de información se ha convertido en el centro de las estrategias, pasando de ser un consumidor a ser un "prosumidor". El ciudadano en los últimos años nos está dando una lección de interacción social, utilizando Internet para canalizar sus deseos y demandas. En este caso hemos elegido por su potencialidad, el turismo en Madrid. Según el Instituto Nacional de Estadística (INE, enero-julio 2016): "La Comunidad de Madrid recibió 42,4 millones de turistas internacionales, lo que supone un incremento del 11,1\% respecto al mismo periodo de 2015 ...". Estos datos avalan nuestro interés por la microsegmentación institucional hacia turistas, hasta ahora considerados minoritarios (por ejemplo turismo de lujo, ecológico, gay, religioso, etc.). Creemos que Madrid tiene posibilidad de convertirse en una ciudad alternativa para un turismo diferente. Este trabajo trata de analizar el turismo cultural religioso a través de las nuevas tecnologías, considerando a un ciudadano/visitante que busca decidir, compartir, diseñar y en definitiva vivir una ciudad on: el turista Halal.

Palabras Clave: Turismo; Microsegmentación; Islam; Mayrit; TICS
\end{abstract}

\begin{abstract}
New technologies have resulted in a change in the consumer's way of living, thinking, travelling, decision-making and purchasing. We live in the society of ubiquity and connectivity. Consumers have adapted to the new reality and, therefore, to the new communication. They demand more participation and decisiveness to the companies and institutions. We, Marketing and Communication experts, work under that adaptation premise. One to one is part of our strategic planning. New technologies are establishing themselves in the Internet environment. Consumers interact with companies and are no longer a mere receiver of the information. They have turned into the focus of the strategies, going from being a consumer to becoming a "prosumer". In recent years, citizens are teaching us a lesson of social interaction, using the Internet to channel their wishes and demands. In this particular case, we have chosen Madrid because of its potentiality. According to the Spanish National Institute of Statistics (INE, January-July, 2016), "The Community of Madrid received 42.4 million of international tourists, which means an increase of $11.1 \%$ with regards to the same period of 2015 [...]". This data supports our interest for the institutional micro segmentation towards tourists considered minorities until now (for example: luxury, ecological, gay, religious tourism...). We believe Madrid has the potential to become an alternative city for a different tourism. This study aims to analyze cultural and religious tourism through new technologies, taking into account citizens/visitors that seek to decide, share, design and ultimately live a city: the Halal tourist. Keywords: Tourism; Microsegmentation; Islam; Mayrit; Tic
\end{abstract}

How to Cite (APA)

Sanchez, P. \& Fernandez-Hernandez, R. (2019). Mayrit on: un nuevo turismo cultural-religioso. International Journal of Professional Business Review, 4 (1), 81-93. DOl 10.26668/businessreview/2019.v4i1.110 


\section{INTRODUCCIÓN}

España ha recibido 9,6 millones de turistas internacionales en julio de 2016, según el Instituto Nacional de Estadística, INE, lo que supone un 9,3\% de incremento respecto al mismo mes del año anterior. Los principales países de procedencia son Reino Unido (con 10.145.091 turistas y un incremento del 15,3\% respecto a los siete primeros meses de 2015), Alemania (con 6.272.370 turistas y un crecimiento del 6,0\%) y Francia (con 6.112.864 turistas y un aumento del 9,5\%)

En cuanto a los destinos elegidos, por Comunidades Autónomas, son: Cataluña con el $25,3 \%$ del total, Islas Baleares $24,7 \%$ y Andalucía con $12,7 \%$. En el resto de comunidades el número de turistas ha aumentado, como en la Comunidad de Madrid, que supuso un 13,4\%. Nuestro trabajo se centra en esta Comunidad Autónoma y más concretamente en la ciudad de Madrid. Antes de comenzar con el análisis de la ciudad, vamos a realizar un análisis de los datos que ratifican nuestra hipótesis de partida: el sector del turismo en la Comunidad de Madrid, necesita un replanteamiento de Comunicación y una nueva microsegmentación de Marketing para sus públicos.

En el periodo enero-julio del año 2016, la Comunidad de Madrid, ha contado con la visita de 42,4 millones de turistas internacionales, lo que supone un incremento del $11,1 \%$ respecto al año anterior.

En cuanto a la procedencia de los turistas, el 20,9\% nos visita desde países latinoamericanos y un $14,8 \%$ lo hace desde Estados Unidos según Instituto Nacional de Estadística, INE, Encuesta de Ocupación Hotelera EOH. En resumen, el número de turistas recibidos en julio 2016 ha sido de 515.374 según el informe FRONTUR, suponiendo un incremento del $16,2 \%$ respecto al mes de junio del año anterior. Estos datos favorables son los que nos ha sugerido una nueva oportunidad de investigación y, por qué no, de negocio. El turista musulmán, pensamos, no está lo suficientemente analizado ni rentabilizado. Nos basamos en datos como que de enero a septiembre de 2015, 71.483 visitantes fueron procedentes de Oriente Medio, una cifra que supone un incremento del $11 \%$ respecto al mismo periodo del año anterior. Evidentemente, no todos los turistas musulmanes proceden de esta zona geográfica pero si nos parece que es un dato importante, teniendo en cuenta que el total de musulmanes en el mundo es de, aproximadamente, 1600 millones (Romero, 2014), lo que supone casi un $25 \%$ de la población mundial. Por otro lado, son los viajeros que más dinero desembolsaron por noche: una media de 179 euros. Así lo revela el último informe de Hotel Price Index, 2015 que ha analizado hasta 40 destinos.

Por otro lado, creemos que también es importante analizar cómo comunica, la ciudad de Madrid, su oferta turística y como interactúa con los turistas. Como plantean González y García (2010) el producto turístico se renueva constantemente, buscando nuevas oportunidades de satisfacer al turista. De esta búsqueda continua, se deriva el papel fundamental que juega, en el sector turístico, la innovación, que ha sido el origen de transformaciones de carácter, no solo general, sino también estructural, lo que nos obliga a analizar estas nuevas circunstancias tanto desde el lado de la oferta como de la demanda. Si queremos conseguir más clientes habrá que interactuar de forma diferente. La digitalización implica cambios en la gestión empresarial e institucional. Si todo cambia y nada es igual, 
habrá que adecuarse a la nueva forma de comunicar y de vender.

En nuestra investigación apostamos por la microsegmentación y la búsqueda de nuevas variables para definir estrategias competitivas. En esa búsqueda encontramos la relación entre Religión y Marketing como una nueva-vieja variable que afecta al consumo y a la decisión de compra. Nos centramos en el Turismo y en concreto en la ciudad de Madrid, por su legado musulmán y por ser una ciudad con la suficiente atracción turística como para plantearse una nueva forma de comunicar $y$ de vender su turismo.

\section{Cultura, Religión e Islam en Marketing Turístico}

Sobre la base de la búsqueda de una definición de Cultura actual y partiendo de que para muchos autores la Cultura es "socialmente conservadora", preferimos recurrir a Bauman (2013) cuando decía: "Bourdieu con la distinción puso patas arriba el concepto original de cultura nacido con la llustración y luego transmitido de generación en generación...De acuerdo con su concepto original, la cultura no debía ser una preservación del statu quo sino un agente de cambio; más precisamente, un instrumento de navegación para guiar la evolución social hacía una condición humana universal". Creemos, como Bourdieu y Bauman, que este cambio constante crea una nueva realidad cultural. Es consecuencia de movimientos migratorios y de la percepción de que el mundo se ha convertido en un mercado único y global.

Constantemente se realizan estudios sociológicos que nos demuestran que el cliente, en este caso turista, decide su compra dependiendo de la estructura social a la que pertenece. Las variables que configuran dicha estructura están compuestas por los diferentes entornos que le rodean: político, económico, tecnológico, demográfico, ecológico $y$, especialmente, el cultural. Por tanto, si buscamos nuevas formas de microsegmentar considerando las diferentes realidades, el entorno cultural y, en concreto, la religión se convierte en una variable imprescindible para poder entender la nueva realidad marketiniana $y$, por ende, turística.

Hoy en día, la cultura no consiste en prohibiciones sino en ofertas, no consiste en normas, sino en propuestas. Tal como señaló Bourdieu (citado en Bauman, 2013), la cultura se ocupa de ofrecer tentaciones y establecer atracciones, con seducción y señuelos en lugar de reglamentos, con relaciones públicas en lugar de supervisión policial: produciendo, sembrando y plantando nuevos deseos y necesidades en lugar de imponer el deber. Si hay algo en relación con lo cual la cultura de hoy cumple la función de homeostato, no es la conservación del estado presente sino la abrumadora demanda de cambio constante. Podía decirse que sirve no tanto a las estratificaciones y divisiones de la sociedad, como al mercado de consumo orientado por la renovación de existencias. La nuestra es una sociedad de consumo: en ella, la cultura, al igual que el resto del mundo experimentado por los consumidores, se manifiesta como un depósito de bienes concebidos para el consumo (Bauman, 2013). Este nuevo concepto de cultura del consumo nos lleva a pensar que estamos ante una nueva realidad empresarial. Los clientes disponen de realidades vividas, "sus realidades", que les hacen tomar decisiones. Estas experiencias se afianzan en su vida creando perfiles de compra. Se impone la máxima personalización en las acciones de Marketing y Comunicación, si el cliente no las siente suyas, no compra el 
producto o, en nuestro caso, no decide ir a un lugar de vacaciones o destino turístico, por lo que debemos plantearnos la búsqueda de nuevos criterios para atraer clientes.

Es entonces cuando surge la pregunta ¿por qué no considerar la Religión como un criterio para definir nuestro próximo destino turístico? El seguimiento de una religión u otra configura una identidad definida por opciones permitidas, aconsejadas, prohibidas o anuladas. Todas las religiones influyen, en mayor o menor medida, en los comportamientos de los consumidores. Cultura y religión se influyen mutuamente. La religión da forma a los sistemas de creencias y prácticas que se inscriben en la cultura particular que le corresponda. La cultura, por su parte, influye sobre los modos de prácticas, la integración religiosa y las creencias necesarias para llevar a cabo sus rituales en la vida social. No hay cultura que actúe ajena a una religión, sea de una forma directa o indirecta. Y no hay cultura desarrollada sin el adecuado entendimiento de su religión (Parekh, 2005 y Sánchez y Padilla, 2013). La religión, en sí misma, pretende aunar la realidad de la humanidad con la realidad universal. Por tanto, la profesión de unas creencias religiosas sirve para legitimar y conservar la realidad de una sociedad. Se convierte en catalizador y herramienta de transformación de la propia cultura de la sociedad que acoge, pudiendo contribuir a la cohesión del conjunto de la sociedad (Garreta, 2003).

Por otro lado y en el caso del Turismo, la posibilidad de elegir un destino identificado con las preferencias religiosas da valor emocional a la decisión de elección, en definitiva, se vive y se viaja como se reza.

En este trabajo se ha tomado como referencia una de las tres religiones, denominadas, del
Libro, el Islam, y ello por varios motivos: evidentemente, por la cercanía en cuanto a raíces culturales; España, históricamente, ha sido tierra habitada por judíos, moros y cristianos, y la historia y el patrimonio cultural del país están plagados de referencias mestizas-mozárabes, sefardíes y mudéjares, que hablan de esa mezcla de culturas. Juderías y morerías son habituales en muchas ciudades y pueblos de España y el mismo lenguaje castellano está cargado de términos provenientes de dichas culturas (Vela y Ballesteros, 2011; Sánchez y Padilla, 2013). Y especialmente en la ciudad de Madrid, como se tratará en detalle más adelante.

También, se ha elegido el Islam, porque los musulmanes tienen una forma de vida marcada por sus normas religiosas. Ellos consideran que su religión supone "una forma de vida".

Analicemos, por tanto, cómo es el Islam. Es una religión monoteísta, revelada entre 610 y 632, d. de C. y estructurada en torno a cinco pilares que todo musulmán debe cumplir: profesión de fe (Shahada), la oración (Salat), la limosna preceptiva (Zaqat), el ayuno (Sawy) durante el mes de Ramadán y la peregrinación (Havy) a los santos lugares de La Meca y Medina, siempre que sea posible. Es este último quinto pilar el que justifica nuestra investigación, el creyente musulmán tiene el "viaje" como uno de sus valores y supone una demostración festiva e introspectiva, en definitiva, como forma de vida.

Además, el Corán define específicamente lo que está permitido, halal y lo prohibido o no aconsejable, haram e incluso determina lo que se considera dudoso y que por lo tanto es no recomendable. Estos conceptos se aplican en todos los sectores que definen su forma de vida: alimentación, finanzas, moda y especialmente en el sector del turismo, en pleno desarrollo por el proceso de globalización y auge económico en 
los países árabes y en el área de Asía Pacífico. Aportaremos algunos datos: en 2020 y siguiendo la estimación de Diner Standar (2012), el 14\% de los viajes será realizado por turistas musulmanes, con una previsión de gasto de 149.000 millones de euros. La industria Halal está valorada en dos billones y medio de dólares anuales y se espera que alcance los diez billones en 2030 (Guerrero, 2014). Creemos que estos datos avalan, y justifican, nuestra investigación.

El modelo de consumo está en constante cambio y el mercado actual también. Así, en el sector del turismo los clientes deciden su destino dependiendo de las calificaciones que aparecen en algunas webs, de las recomendaciones que tienen de sus conocidos y amigos realizando acciones de member get member. Parece, por tanto, que se trata de personalizar al máximo la oferta buscar el lado emocional con el que se pueda sentir identificado el futuro cliente. Es aquí donde creemos que está la clave, si lo que se busca es captar criterios personalizados, la religión se convierte, en una de las nuevas-viejas variables y el Turismo Halal aparece como alternativa y gran oportunidad de negocio por lo que el turista musulmán se convierte en objetivo empresarial.

En este caso aplicado al sector turístico en la ciudad de Madrid. Tras la revisión de la literatura, podemos afirmar que no hay todavía en Madrid, ningún estudio académico que relacione, desde esta perspectiva marketiniana y de comunicación de ciudad, Islam y Turismo.

\section{De Mayrit a Madrid una realidad turística on}

La Organización Mundial del Turismo (OMT) estableció en 2001 las siguientes tipologías turísticas: turismo de sol y playa, turismo cultural, turismo de negocios, turismo religioso, turismo idiomático, turismo de salud, turismo de la naturaleza y turismo deportivo. Además de estas tipologías creemos que hoy en día, también hay turismo experiencial, sostenible, con mascotas, homosexual, de lujo, para singles, sólo para mujeres, etc. Cada una de estas acepciones supone una oportunidad en el nuevo turismo. El desarrollo de las nuevas tecnologías, entendiendo por estas "Dispositivos tecnológicos (hardware y software) que permiten editar, producir, almacenar, intercambiar y transmitir datos entre diferentes sistemas de información que cuentan con protocolos comunes. Estas aplicaciones, que integran medios de informática, telecomunicaciones y redes, posibilitan tanto la comunicación y colaboración interpersonal (persona a persona) como la multidireccional (uno a muchos o muchos a muchos). Estas herramientas desempeñan un papel sustantivo en la generación, intercambio, difusión, gestión y acceso al conocimiento". Romaní (2011) supone un potencial en desarrollo en el ámbito del turismo. Hoy en día el turista busca información, genera información y para ello utiliza las nuevas tecnologías como herramienta para difundir sus mensajes, convirtiéndose en prosumidor, "son personas que consumen lo que ellos mismos producen" (Toffler, A., 1980; Sánchez, J. y Contreras, P., 2012).

En el informe Muslim Business Traveler Insights 2016 se puede observar la importancia de Internet para el turista halal, consideran el servicio de Wi-Fi como el más importante en su alojamiento en los viajes de negocios. 


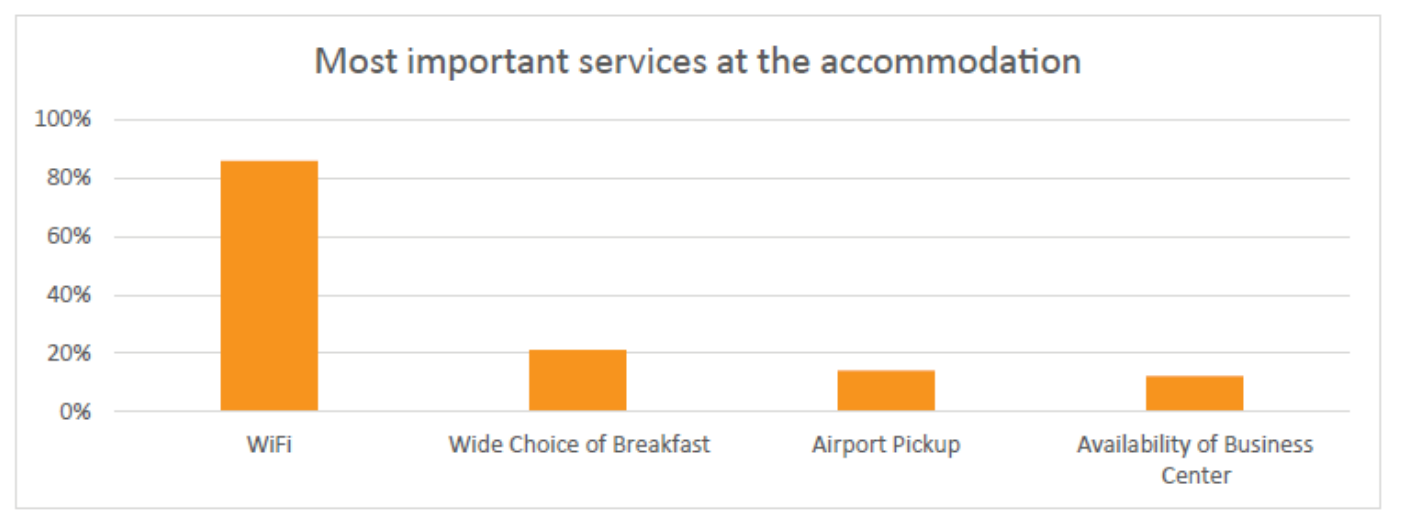

Grafico 1 - Servicios más importantes en el alojamento

Fuente: Informe Muslim Business Traveler Insights 2016

Siguiendo a Andújar (2014), el turismo islámico se define como "cualquier actividad, evento y experiencia que suponga una forma de viajar acorde con el Islam". Y si tenemos en cuenta que en la comunidad de Madrid, dentro del sector servicios, el turismo alcanza una de las posiciones más relevantes, con una incidencia notable en la actividad económica. Al estar basada la actividad turística madrileña, principalmente, en la motivación profesional y de negocios, su desarrollo ha estado estrechamente vinculado a la evolución de dicha actividad económica. Sin embargo, esta orientación tiende cada vez más a asociarse con actividades de ocio, siguiendo las tendencias mundiales, por lo que destinos como Madrid, con un componente destacado en oferta cultural y de esparcimiento, se configura como importante foco de atracción turística, Vacas (2000). Por tanto, creemos que podemos plantearnos el Turismo Halal como una alternativa on para la ciudad de Madrid. Principalmente porque Madrid fue Mayrit.

Madrid es la única capital europea cuyos orígenes y denominación están vinculados a lo árabe. Son muy pocos los que lo saben. Con la herencia de al-Andalus se identifican ciudades españolas cuya historia las hizo desempeñar un importante papel político y, por tanto, dejaron una huella monumental (la Alhambra, la Mezquita de Córdoba, etc.). No es el caso de Madrid, cuyos orígenes defensivo y fronterizo no la convirtió en una gran estructura urbana dotada de ricos monumentos. Y más o menos así continuó hasta que Carlos III quiso convertirla en una capital monumental. Para entonces, sus vestigios pasados habían ido desapareciendo o difuminándose en el contorno urbanístico de la villa. Esa falta de visibilidad ha facilitado el ocultamiento y la ignorancia sobre sus siete siglos de pasado árabe, satisfaciendo la mentalidad oficial de una España que, regida por el paradigma ideológico de los Reyes Católicos, hacía tabla rasa de su pasado musulmán (Martín, 2011).

Las crónicas atribuyen la fundación de Madrid a Abu I-Mundir Muhammad ibn'Abd al-Rahman Muhammad I (quinto emir independiente de Córdoba) que reinó durante casi 34 años. Como plantea Gil -Benumeya (2015) a su gestión se deben hermosas obras, muchas gestas, grandes triunfos y total cuidado por el bienestar de los musulmanes, preocupándose por sus fronteras, guardando sus brechas, consolidando sus lugares extremos y atendiendo a sus necesidades. Él fue quien ordenó construir el castillo de Esteras (Istirash), para las cosechas de Medinaceli y él 
fue quien construyó para la gente de la frontera de Toledo el castillo de Talamanca (Talamanka) y el castillo de Madrid (Mayrit).

Por otro lado, Segura (2004) plantea que se ha especulado con la posibilidad de que Madrid fuera en sus orígenes una de tantas fortalezas fundadas por rebeldes, que habría acabado por pactar su sumisión con 'Abd al-Raaman III, el cual, a cambio, habría dotado a la plaza la condición de madina o ciudad. En el año 932 Mayrit quedaría conformada por un alcázar y una medina enclaves fortificados con sus respectivas murallas y fosos, y finalmente unidos los recintos por un albacar (Andreu, 2011). También hay que considerar lo que Gil-Benumeya (2015) propone, un recorrido posible por aquel castillo nacido en el nebuloso territorio de una frontera medieval, al que sus fundadores dieron el nombre de Mayrit y que evolucionó para convertirse en una pequeña ciudad de los confines del mundo islámico. Nuestra historia sigue tras la incorporación de Madrid al Reino de Castilla mostrando una ciudad en la que judíos y musulmanes coexistieron con los cristianos, donde siguió habiendo una mezquita y una casa da baños. Por tanto, la historia de Madrid tiene mucho de Mayrit. Así, nuestro planteamiento de investigación supone una adecuación del legado musulmán a la comunicación turística, actual, de la ciudad, intentando conseguir una ciudad friendly- halal, es decir, adaptada al turista halal.

Analicemos ahora cuáles son los datos turísticos que se refieren a nuestro objeto de estudio, que es la ciudad de Madrid, en 2016 llegaron 9.034.327 turistas de los cuales 4.433.857 son turistas nacionales y 4.600 .470 extranjeros. En cuanto al lugar de procedencia de los turistas extranjeros proceden principalmente de Estados Unidos 567.710, Reino Unido 361.992, Italia 342.366, Francia 314.226, según los datos del Vademécum Turístico de Madrid de diciembre de 2016. Estas cifras nos confirman la recuperación del turismo de la Ciudad de Madrid en los últimos años, como se puede apreciar en el siguiente cuadro, clasificado por orden número de visitantes.

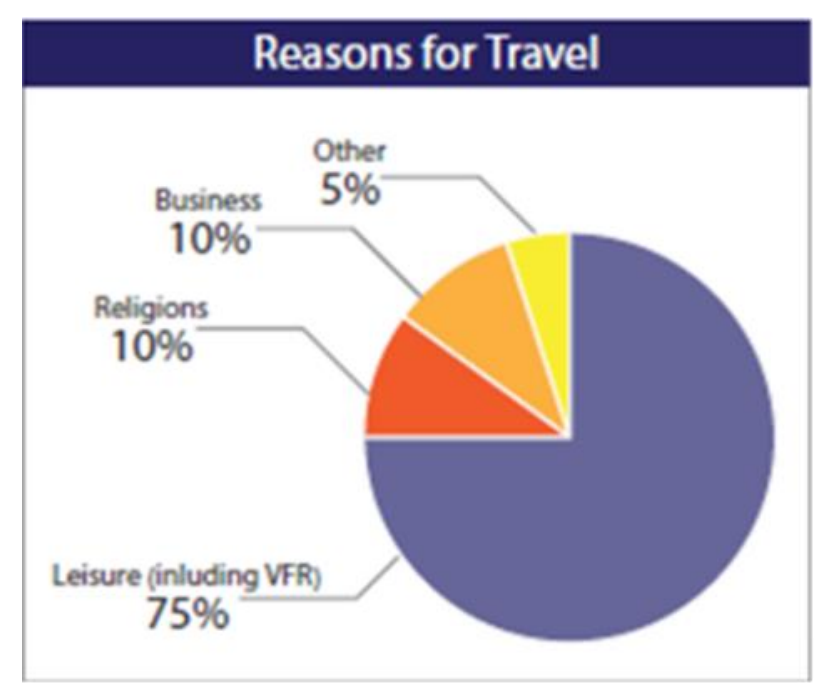

Grafico 2 - Servicios más importantes en el alojamento Fuente: Informe Muslim Business Traveler Insights 2016

La actividad turística supone 9.546 millones de euros, lo que representa el 7,7\% del PIB y el
8,3\% de la actividad turística nacional. El perfil del visitante, de la ciudad de Madrid, responde a 
las siguientes características: Jóvenes de 25 a 44 años y Adultos de 45 a 64 años, Ingresos medios / medios-altos, Buscan: Ocio, patrimonio cultural y gastronomía. Parejas sin hijos y grupos de amigos, Estancia media: 2 noches. La ciudad de Madrid tiene la capacidad y el equipamiento necesario para poder cubrir las necesidades de estos turistas, pudiendo ofrecer gastronomía, patrimonio y arquitectura, deporte y ocio, shopping así como una completa oferta hotelera y una magnífica infraestructura de transportes. Según la encuesta de movimientos turísticos en fronteras (Frontur), la región de Madrid recibió, de enero a septiembre de 2015, 71.483 visitantes procedentes de Oriente Medio, una cifra que supone un incremento del $11 \%$ respecto al mismo periodo del año anterior. Como se ha comentado anteriormente las previsiones respecto al turista musulmán, es que suponga un incremento muy importante para aquellas ciudades que sepan ofrecerles una oferta turística que cubra sus necesidades marcadas por su religión. Es un turista con un gran potencial económico, ávido de conocer nuevos destinos y de consumir en ellos, las principales razones de sus viajes son ocio, religión, negocios y otros.

\section{Muslim visitor arrivals (in millions) from 1995 to 2020 (projection)}

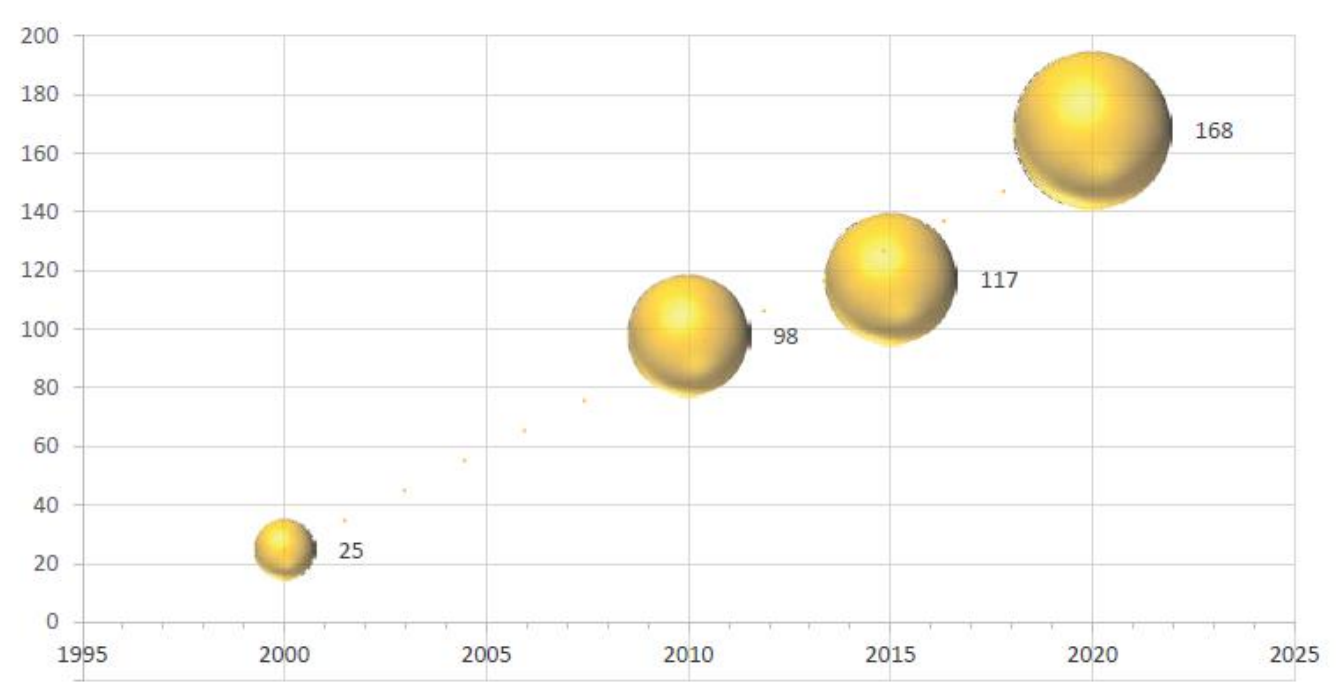

Grafico 3 - Llegadas de visitantes musulmanes (en millones) de 1995 a 2020 (proyección) Fuente: Informe Muslim Business Traveler Insights 2016

La ciudad de Madrid, por tanto, tiene un gran reto si quiere captar al turista musulmán. El de adaptar su oferta a un cliente exigente, que demanda poder visitar la ciudad sin tener que renunciar a su estilo de vida. Madrid tiene una gran oportunidad para conquistar a estos turistas si es capaz de comunicar su oferta turística ofreciéndole adecuación de los servicios, por ejemplo, habitaciones orientadas a la Meca, un
Corán en la mesilla, salas separadas para las mujeres, servicio de habitaciones femenino $y$ espacio para que puedan realizar sus oraciones, además de comedores donde no se sirva alcohol y cualquiera de los servicios que puedan demandar: canales de televisión, folletos traducidos, información sobre los servicios religiosos, etc. $Y$ este es también nuestro objetivo, realizar una investigación académica - 
profesional para comprobar la viabilidad de esta microsegmentación que en otros países y ciudades es ya una realidad.

\section{Consideraciones finales}

Este trabajo forma parte de las investigaciones realizadas desde el grupo de investigación académíco-cientifíca, de ESIC, Cultumar, que desde 2015 está llevando a cabo investigaciones para medir y diagnosticar estudios que tengan que ver con nuestras áreas de actividad, especialmente en Marketing, Comunicación y Turismo. Es un grupo interdisciplinar, interuniversitario $y$, próximamente, internacional. Con espíritu global y dispuesto a colaborar con cualesquiera de los investigadores que se presten a aumentar nuestra capacidad de análisis y de estudio. Nuestra filosofía de trabajo es off - on y abierta a compartir.

En estos momentos, nos encontramos en el inicio de la investigación académica. En una primera fase, se ha realizado un estudio bibliométrico que ha consistido en recopilar y analizar artículos publicados en revistas científicas durante un periodo de varios meses. Las fuentes de información secundarias consultadas han sido las bases de datos universitarias, nacionales e internacionales y las encontradas en organismos oficiales. Especialmente centradas en Turismo, Cultura y Religión y específicamente orientadas a la ciudad de Madrid. Actualmente se está diseñando una investigación cualitativa, para realizarla en el último trimestre del presente año, basada en entrevistas semiestructuradas, a empresarios turísticos e instituciones de la ciudad. Y, a principios de 2018, como consecuencia de los resultados del análisis cualitativo, se realizará una encuesta personal y autocumplimentada, en estos momentos en fase de diseño, a un público objetivo definido entre pre-profesionales del sector turístico y empresarial en la ciudad de Madrid.

Una vez analizada la relación del tratamiento del Marketing, la Religión, el Islam y Madrid hemos llegado a la conclusión de que representa un colectivo digno de ser valorado por las empresas e instituciones madrileñas en sus próximas estrategias de segmentación. Si lo que se busca es captar a los clientes de forma personalizada, la religión es una de las variables más íntima y experiencial, creemos, para conseguirlo.

Como principal conclusión podemos decir que nuestra apuesta debe ser contemplada como una alternativa a la globalización, y en definitiva a la planificación estratégica de uno de los sectores empresariales más importantes de España y, por ende, de Madrid: el Turismo.

Compartimos con Vacas (2000) que Madrid posee una alta significación cultural, y en la ciudad se concentra la mayor parte del patrimonio histórico, artístico y cultural de la región y una buena representación del patrimonio del país. Por lo que creemos que el enfoque dirigido hacia el turista musulmán es posible, el legado de la ciudad lo justifica.

Tratar el Islam en Marketing puede parecer arriesgado en España, sin embargo hace ya unos cuantos años que en otros países se utiliza el concepto "Islamic Marketing", así autores como Nestorovic (2010) se planteaban adecuaciones de los las famosas 4 p's: product, price, place y promotion, a las 4 f's del mercado musulmán: faith, food, finance y fashion. Creemos, con humildad, que habría que añadir una quinta $f^{\prime}$ que, sin serlo, puede llegar a ser tan importante como el resto, el Turismo Halal. 
Y para finalizar, señalar que la adecuación a un nuevo tipo de cliente no podría realizarse sin "un cambio de mirada". Necesitamos cambiar la forma de planificar si queremos captar a nuevos clientes. El nuevo mercado exige la búsqueda de alternativas. El marketing one to one se impone, estamos llegando a la máxima personalización de las ofertas turísticas. Si el mix de medios es off y on, acerquémonos a una nueva realidad, la del turista musulmán.

Esperamos contar, próximamente, con los resultados de la investigación en la que estamos inmersos. Comprobando así que nuestra hipótesis de partida se puede corroborar: Mayrit se merece otras estrategias para ser visitada. La microsegmentación es posible. El big data permite adecuar las ofertas turísticas. Si el cliente es off y on, podemos llegar con la virtualización de la oferta cultural a cualquier parte del mundo y mostrarles el ayer, para que entiendan y disfruten el hoy y que vuelvan, y nos recomienden, mañana.

\section{Glosario}

Para finalizar hemos creído necesario anexar un pequeño glosario con algunos de los conceptos básicos para entender la realidad del Turista Halal. Para ello, y después de consultar diferentes fuentes, hemos pensado que El Muslim/Halal Travel Market (Basic concepts, terms and definitions) (2015) by CrescentRating, nos aportaba los términos que a continuación aportamos.

- Halal: El término árabe para permisible. Significa permisible según las reglas de Islam. Es el más con frecuencia mandado a en cuanto a la comida, pero incluye cualquier tipo de acción permisible en Islam.
-Haram/Non-Halal: Se refiere a lo que se considera prohibido o no recomendable bajo enseñanzas islámicas. A menudo se usa en la conjunción con Halal, a menudo en cuanto a la comida, pero también se puede referir a otras acciones ilegales en Islam como robo, corrupción etc.

-Muslim travellers: Los musulmanes que viajan.

-Halal-conscious traveller: Los viajeros musulmanes que no desean poner en peligro sus necesidades basadas en la fe viajando.

-La opinión de CrescentRating: El nivel de adhesión a la fe de sus necesidades y que puede variar de un viajero al otro. Como tal, este término se refiere a viajeros musulmanes que buscan, al menos, alguna forma de una necesidad basada en la fe viajando. La gran mayoría de musulmanes buscará por lo menos la comida Halal.

-Destino Halal-Friendly: Los destinos que proporcionan servicios e instalaciones que satisfacen, al menos, algunas necesidades basadas en la fe de invitados musulmanes a los destinos.

-Cuarto del rezo: Generalmente encontrado en aeropuertos, hospitales etc. Son por lo general en el área de tránsito o en espacios públicos. Son requeridos para realizar rezos, meditación etc. Estos cuartos también pueden contener esteras del rezo, horarios del rezo, copias de Qur'an y un signo en dirección a la qiblah. 
-Mezquita: La casa musulmana sagrada de adoración dedicada a rezos diarios y otras acciones religiosas. Se diferencia de un cuarto del rezo simple en que un Imám (líder del rezo) oficialmente conduce a los fieles, diariamente, en sus cinco rezos.

-Tiempos de Prayer/Salah: Los cinco rezos diarios obligatorios (Salah) en el Islam se Ilaman Fajr (alba), Dhuhr (tarde), Asr (tarde en la tarde), Maghrib (puesta del sol) e Isha (noche), cada uno que tiene timings específicos según la posición del sol a lo largo del día. Como tal, los tiempos del rezo varían según la época del año y ubicación. En cualquier país, las comunidades

\section{REFERENCIAS}

Andreu, E. (2011). La arqueología como determinante para el conocimiento del origen de Madrid, en Flores, D. (Ed.). De Mayrit a Madrid. Madrid y los árabes, del siglo IX al siglo XXI. Casa Árabe. Madrid.

Andújar, N. (2014). La formación en el sector del Turismo Halal, en de la Orden, C. y Sánchez, P. (coords). Turismo halal en España. OMM. Madrid.

Bauman, Z. (2013). La cultura en el mundo de la modernidad líquida. Fondo de Cultura económica. Madrid.

Estadística de Movimientos Turísticos en Fronteras (FRONTUR) Extraído el 5 de septiembre de 2016 de http://www.ine.es/daco/daco42/frontur/f rontur0716.pdf

Estudio Hotel Price Index (2015). Extraído el 5 de septiembre de 2016 de musulmanas locales por lo general proporcionan la información a timings específicos. También hay muchos apps móviles, que proporcionan tiempos del rezo a cualquier ubicación.

-Tiempos del rezo en vuelo: Sabiendo los tiempos del rezo a bordo en particular debido a los husos horarios que cambian continuamente y la posición del Sol. La Calculadora del Tiempo del Rezo de Viaje en avión de CrescentRating, ahora disponible en HalalTrip app móvil provee tiempos del rezo así como la dirección qiblah a lo largo de la trayectoria de vuelo para cualquier vuelo.

http://hpi.hotels.com/es-h22015/paisesque-mas-gastan-en-espana/

Garreta, J. (2003). La integración sociocultural de las minorías étnicas. Anthropos. Barcelona.

Gil-Benumeya, D. (2014). Madrid Islámico. La librería. Madrid.

González, R, y García, F. E. (2010) Los blogs y los portales de servicios, las nuevas herramientas del marketing relacional en el turismo rural. En Turydes, Revista de Investigación en turismo y desarrollo local. Vol. 3, no 7. Abril.

Guerrero, T. (2014): ¿Un "hub halal" global? Cinco días. Extraído el 10 de septiembre de 2016.

http://cincodias.com/cincodias/2014/01/1 6/empresas/1389897757_894895.html Instituto Nacional de Estadística de España. Extraído el 5 de septiembre de 2016 de 
http://www.ine.es/daco/daco42/frontur/f rontur1215.pdf

Informe Hoteles.com Hotel Price Index 2015. Extraido el 9 de enero de 2017 http://hpi.hotels.com/es-h22015/paisesque-mas-gastan-en-espana/

Informe Muslim/Halal Travel Market. Basic concepts, terms and definitions (2015) by CrescentRating. Extraido el 8 de febrero de 2017

https://www.crescentrating.com/onlinehalal-travel-glossary.html

Informe Muslim Business Traveler Insights 2016. Extraido el 8 de febrero de 2017 https://newsroom.mastercard.com/asiapacific/files/2016/10/Report-MastercardCrescentRating-Muslim-Business-TravelerInsights-2016.pdf

Instituto Nacional de Estadística http://www.ine.es/daco/daco42/frontur/f rontur0716.pdf Extraido el 26 de enero de 2017.

Martín, G. (2011). Una herencia olvidada, en Gil, D., De Mayrit a Madrid. Madríd y los árabes, del siglo IX al siglo XXI. Casa Árabe. Madrid.

Nestorovic, C. (2010). Marketing Islamico. Egea.Milán

Parekh, B. (2005). Repensando multiculturalismo. Istmo. Madrid.

Romero, I. (2014). El concepto de la marca de garantía Halal, en de la Orden, C., y
Sánchez, P. (Coord.) Turismo Halal en España. Omm. Madrid.

Romaní, J. C. C. (2011). El concepto de tecnologías de la información. Benchmarking sobre las definiciones de las TIC en la sociedad del conocimiento. ZerRevista de Estudios de Comunicación, 14 (27).

Sánchez, P. y Padilla, G. (2013). La importancia del tratamiento de la religión en medios de comunicación. El caso del Islam en España, en Estudios sobre el Mensaje Periodístico, no 19, pp. 449-457.

Sánchez, P. (2014). La religión en el marketing, variable imprescindible en la búsqueda del turista musulmán en de la Orden, C., y Sánchez, P. (Coords.) Turismo Halal en España. Omm. Madrid.

Segura, C. (2004). El origen islámico de Madrid y las relaciones con los reinos cristianos, en Turina, A., Quero, S. y Pérez, A.(Coords.) testimonios del Madrid medieval: el Madrid musulmán. Ayuntamiento de Madrid, Museo de San Isidro. Madrid.

Turismo de Madrid. Extraído el 5 de septiembre de 2016 de http://turismomadrid.es/attachments/arti cle/11708/Avance\%200EH\%20+\%20FRON TUR+\%20EGATUR_JUNIO_2016[1].pdf

el Vacas, T. (2000) los museos madrileños como oferta turístico-cultural. En Cuadernos de Turismo, no 5, pp 105-111. 
Vademécum turístico de Madrid (2016) Centro de inteligencia turística. Extraído el 15 de enero de 2017 de

http://www.madrid-

destino.com/images/Dossier/Estadisticas/ VADEMECUM_DICIEMBRE_2016.pdf
Vela, C. y Ballesteros, C. (2011): La influencia de las creencias religiosas en el consumo. Una aproximación desde las tres religiones del Libro, en Revista de las Facultades de Derecho y Ciencias Económicas y Empresariales. Madrid, ICADE, pp.361-392. 